\title{
Experimental validation of a GIS-based procedure for predicting pesticide exposure in surface water
}

\author{
Sara Bonzini ${ }^{1}$, Roberto Verro ${ }^{1}$, Stefan Otto $^{3}$, Luca Lazzaro ${ }^{2}$, Antonio Finizio ${ }^{1}$, Giuseppe Zanin ${ }^{2}$, \\ Marco Vighi ${ }^{1}$ \\ ${ }^{1}$ University of Milano Bicocca, Department of Environmental Sciences, Piazza della Scienza 1, \\ 20126 Milano, Italy \\ ${ }^{2}$ University of Padova, Department of Environmental Agronomy and Crop Science, Agripolis \\ Campus, Viale dell'Università 16, 35020 Legnaro (PD), Italy \\ ${ }^{3}$ National Council of Research, Institute of Agro-environmental and Forest Biology, Agripolis \\ Campus, Viale dell'Università 16, 35020 Legnaro (PD), Italy
}

\section{Supporting Information Contents}

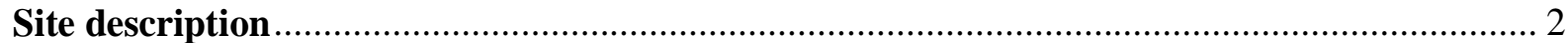

Table 1. Land use in the Meolo basin in 2003 and 2004 ..................................................... 2

Structural formulas of the selected compounds ................................................................ 2

Table 2. Physical-chemical properties and persistence of the selected pesticides. Data are taken

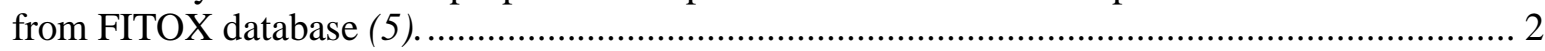

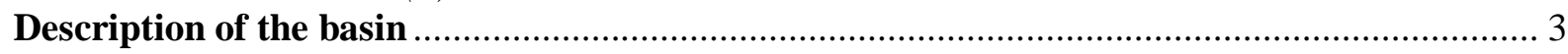

Figure 1. Digital Terrain Model (DTM) of Meolo basin..................................................... 3

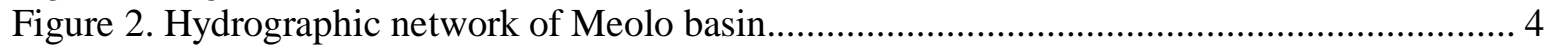

Figure 3. Soil organic carbon content of Meolo basin.............................................................. 5

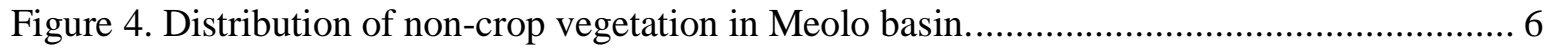

Figure 5. Weather stations and areas of influence.......................................................... 7

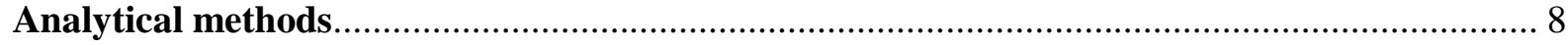

Table 3. Analyte selected ions for SIM-detection, retention times, mean recovery, standard deviation and limits of detection (LOD) in $5 \mathrm{~L}$ water samples and $2.3 \mathrm{~g}$ suspended matter......... 9

Results.

Table 4. Concentrations ( $\mu \mathrm{g} / \mathrm{L})$ of the selected chemicals in samples collected manually at the stations Spring, Rovarè and Castelletto in February (before productive season) and from April to October 2004 (n.d.: below LOD; traces: below LOQ).

Table 5. Concentrations $(\mu \mathrm{g} / \mathrm{L})$ of the selected chemicals in samples collected by automatic sampler at the Monastier station from April to October 2004. Values reperesent daily averages of

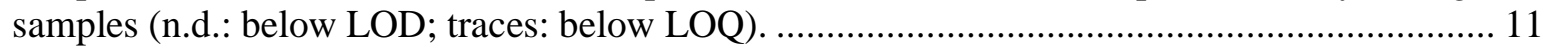

Comparison between automatic and manual samples..................................................... 12

Figure 6. Comparison of terbuthylazine concentration in the automatic sampler station of Monastier and in the manual sampling station of Castelletto......................................... 12

Correlation between predicted and measured concentrations............................................. 13

Figure 7. Linear and logarithmic correlations between predicted and measured (autosampler) concentrations for terbuthylazine.

Figure 8. Linear and logarithmic correlations between predicted and measured (autosampler) concentrations for metolachlor. 


\section{Site description}

Table 1. Land use (in hectares) in the Meolo basin in 2003 and 2004.

\begin{tabular}{l|c|c|}
\multicolumn{1}{c|}{ Crop } & $\mathbf{2 0 0 3}$ (ha) & 2004 (ha) \\
\hline Maize & 817 & 826 \\
Soybean & 627 & 443 \\
Vineyards & 356 & 386 \\
Sugar beet & 111 & 98 \\
Wheat and barley & 81 & 210 \\
Other crops, or non cultivated and urban areas & 886 & 915 \\
\hline Sum & 2878 & 2878 \\
\hline
\end{tabular}

Structural formulas of the selected compounds<smiles>COC(=O)C1N=C(NC2CC(Cl)NC(OC)C2)C(C)(C)O1</smiles>

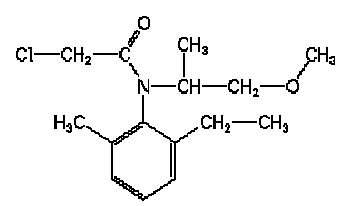

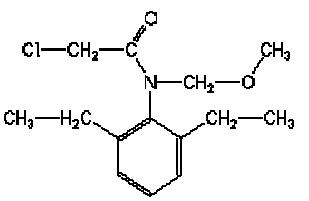<smiles>CON(C)C(=O)NC1CCC(Cl)C(Cl)C1</smiles><smiles>CO[PH](S)(OC)OC1CCC([N+](=O)[O-])C(C)C1</smiles>

TERBUTHYLAZINE

METOLACHLOR

\author{
ALACHLOR
}

LINURON

FENITROTHION

Table 2. Physical-chemical properties and persistence of the selected pesticides. Data are taken from FITOX database (5).

\begin{tabular}{|l|c|c|c|c|c|c|}
\hline \multicolumn{1}{|c|}{ Chemicals } & $\mathbf{M W}$ & $\begin{array}{c}\mathbf{W S} \\
\mathbf{m g} / \mathbf{L}\end{array}$ & $\begin{array}{c}\mathbf{V P} \\
\mathbf{P a}\end{array}$ & $\log \mathbf{K}_{\mathbf{o w}}$ & $\log \mathbf{K}_{\mathbf{o c}}$ & $\begin{array}{c}\text { DT50 soil } \\
\text { days }\end{array}$ \\
\hline terbuthylazine & 229.7 & 8.5 & $1.5 \mathrm{E}-04$ & 2.88 & 2.44 & 60 \\
\hline metolachlor & 283.8 & 530 & $4.2 \mathrm{E}-03$ & 3.28 & 2.46 & 46 \\
\hline alachlor & 269.8 & 240 & $2.9 \mathrm{E}-03$ & 3.01 & 2.23 & 30 \\
\hline linuron & 249.1 & 75 & $2.0 \mathrm{E}-03$ & 2.76 & 2.60 & 60 \\
\hline fenitrothion & 277.2 & 30 & $1.3 \mathrm{E}-04$ & 3.40 & 3.30 & 16 \\
\hline
\end{tabular}




\section{Description of the basin}

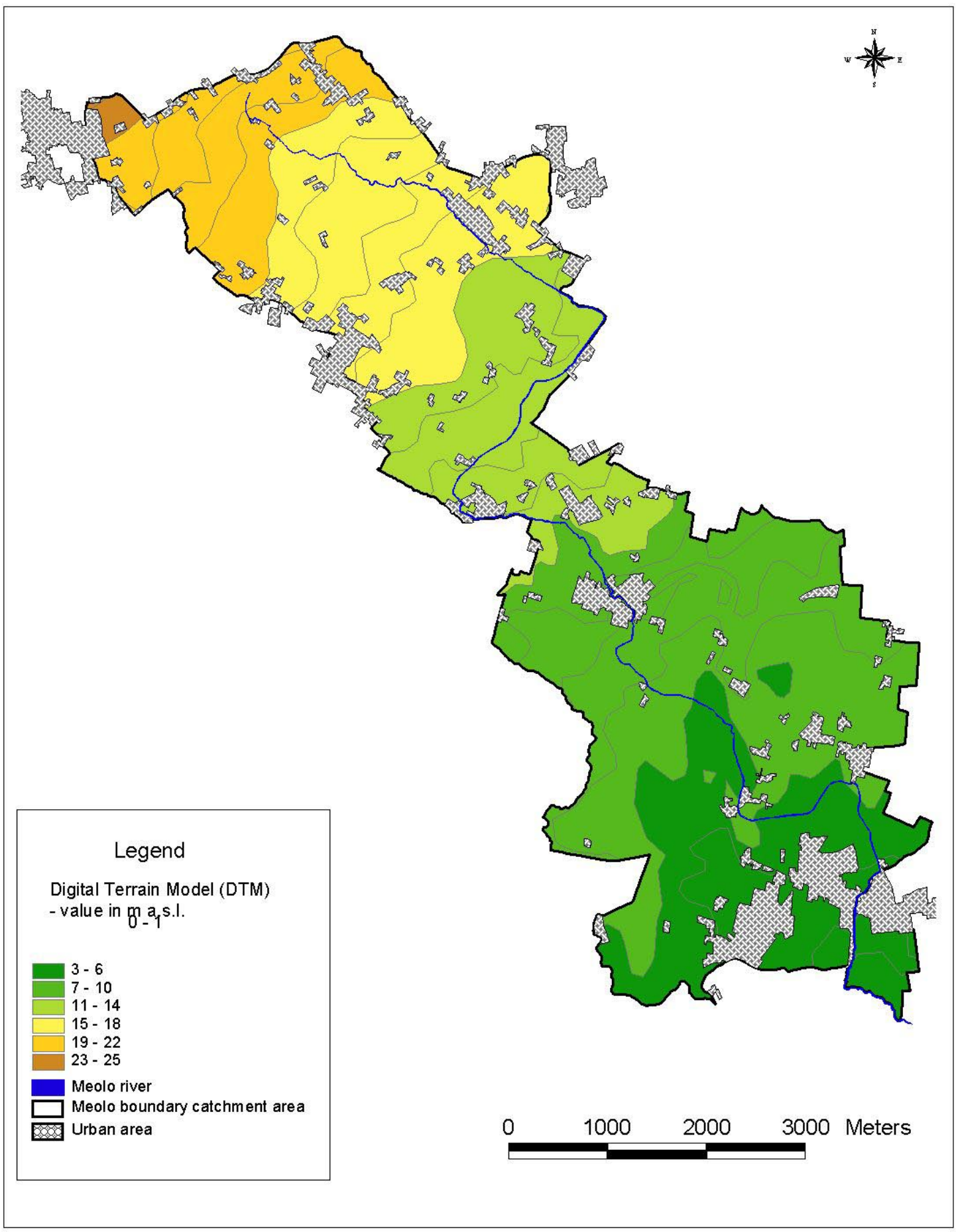

Figure 1. Digital Terrain Model (DTM) of Meolo basin. 


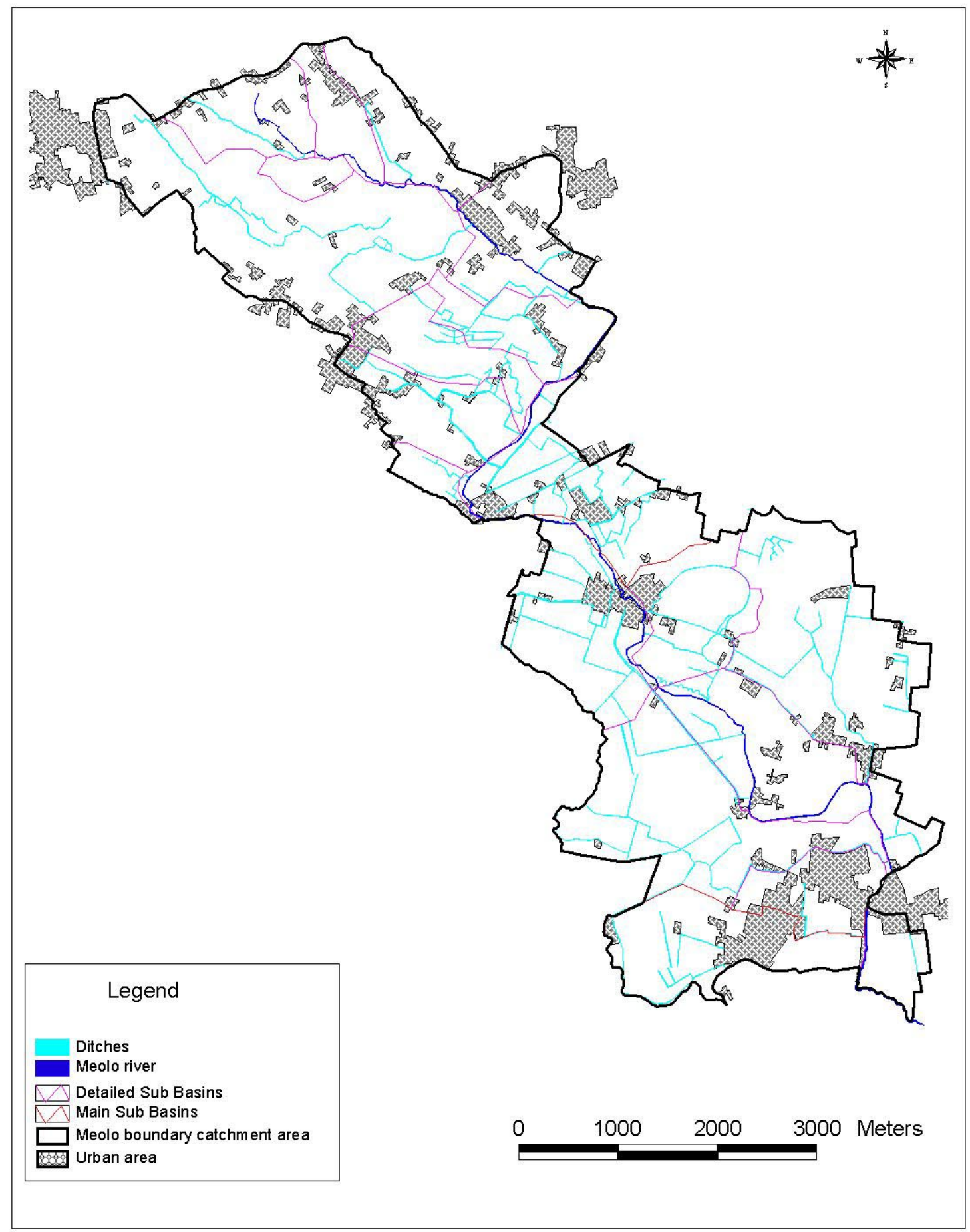

Figure 2. Hydrographic network of Meolo basin. 


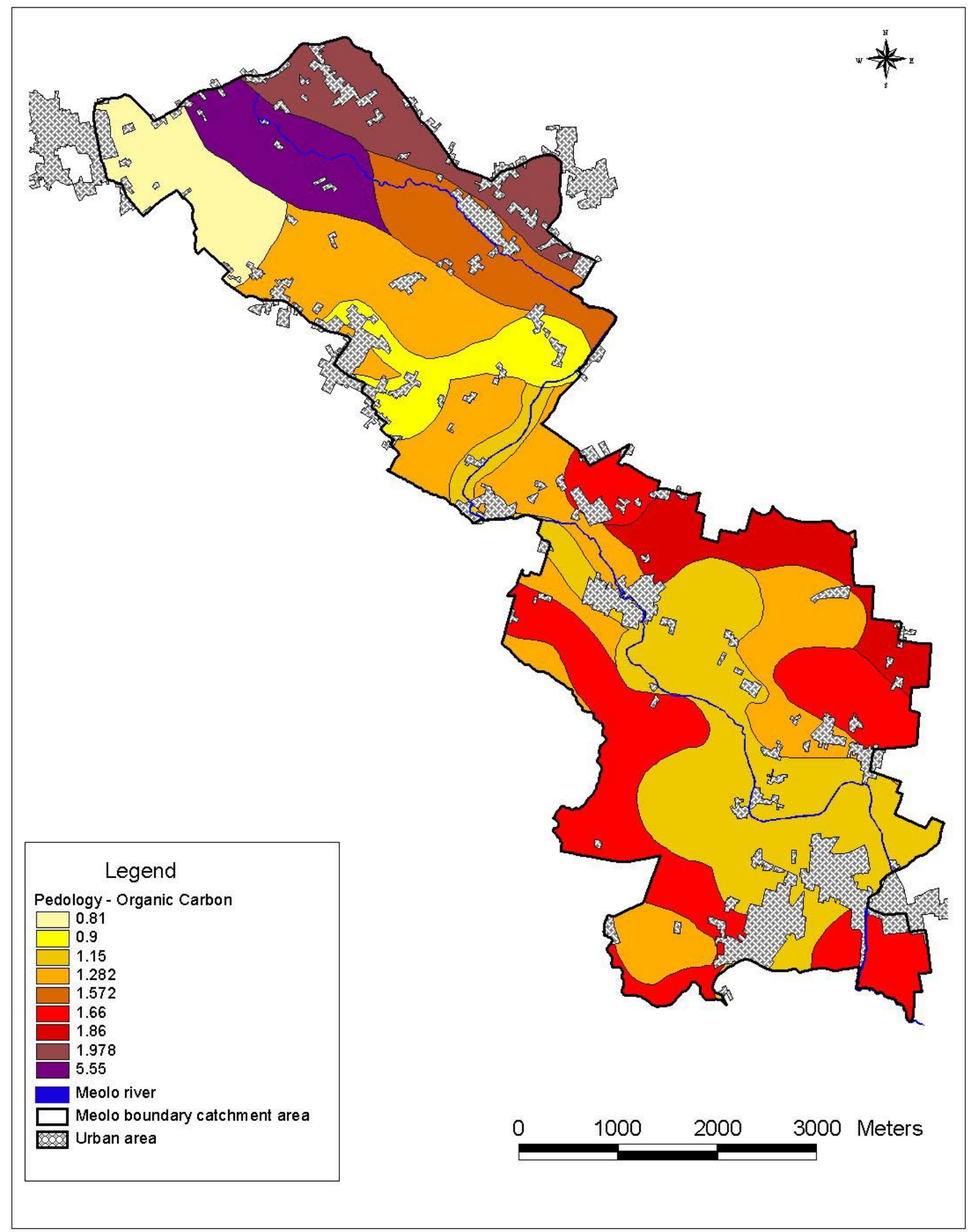

Figure 3. Soil organic carbon content of Meolo basin. 


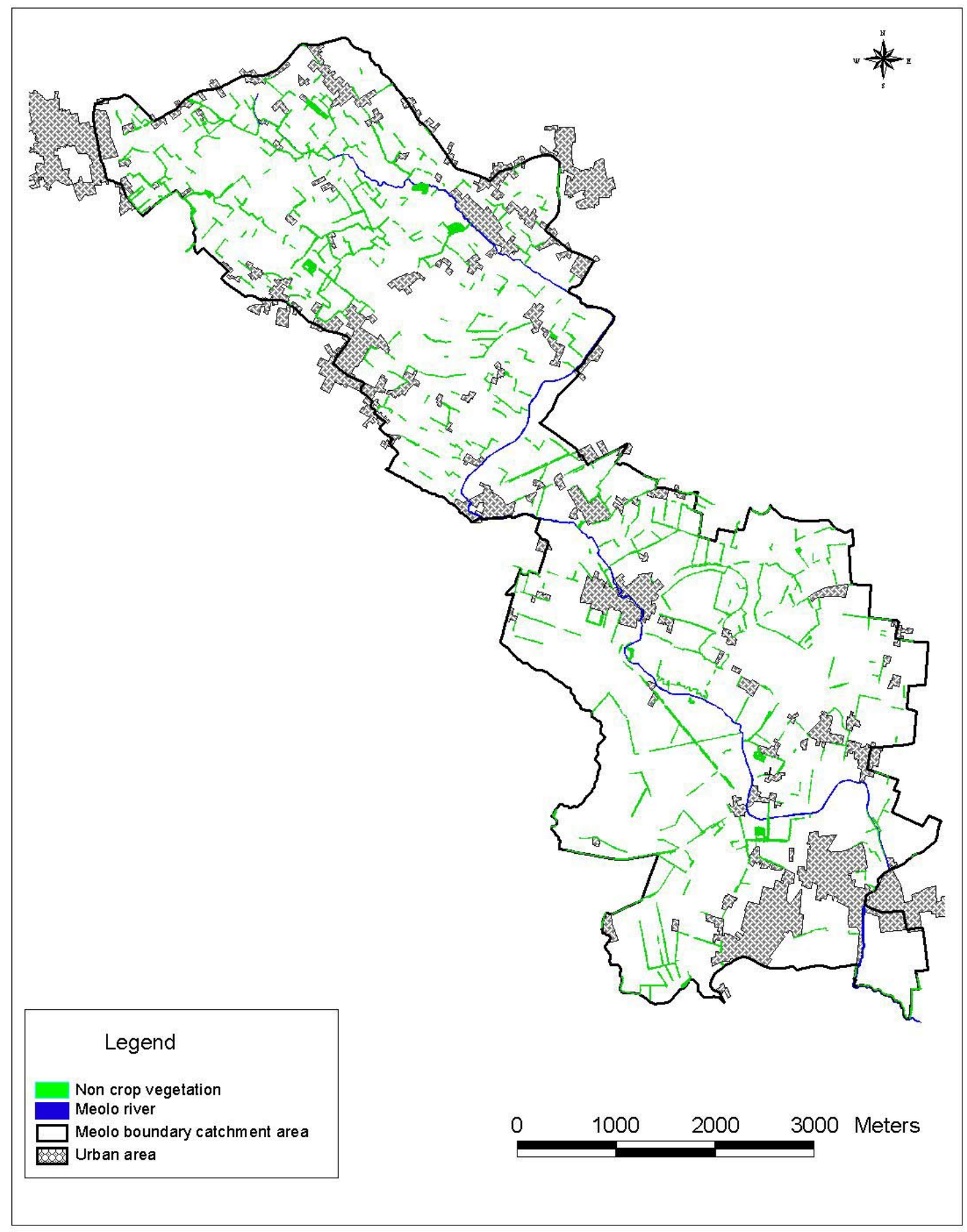

Figure 4. Distribution of non-crop vegetation in Meolo basin. 


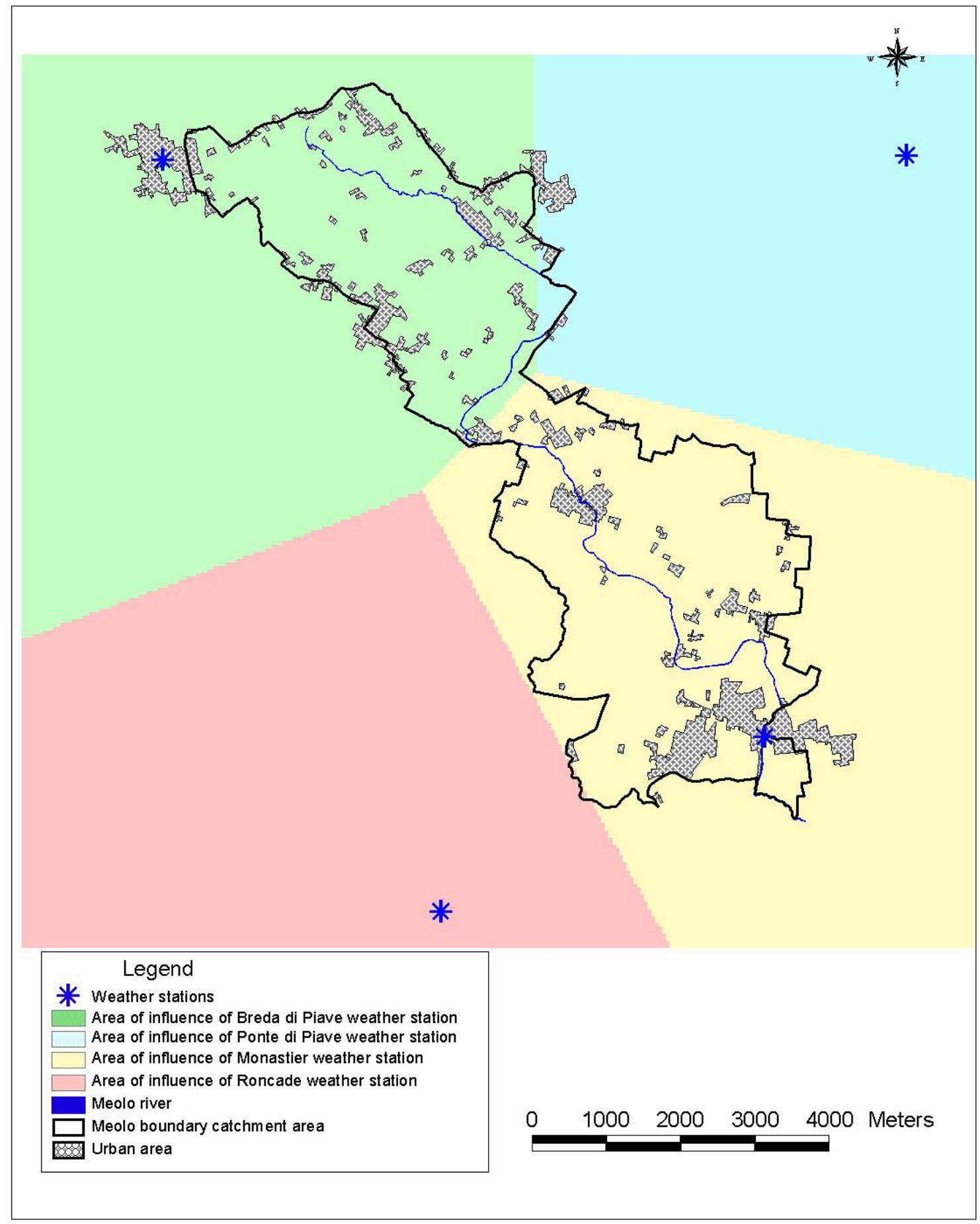

Figure 5. Weather stations and areas of influence. 


\section{Analytical methods}

Chemical analyses were performed according to the methods of Pastias and PapadopoulouMourkidou (10) and of De Almeida Azevedo et al. (11) with some modifications.

All solvents used (ethyl acetate, methanol and hexane) and the pesticide analytical standards were purchased from Riedel de Haen (Hannover, Germany). Anhydrous sodium sulphate was supplied by Carlo Erba (Milano, Italy), $\mathrm{C}_{18}$ for SPE extraction by Alltech (Milano, Italy), Florisil by Fluka (Milano, Italy) and membrane filters $(0.45 \mu \mathrm{m})$ by Millipore (Bedford, MA, USA).

Water samples, from $0.8 \mathrm{~L}$ (auto sampler) to $\sim 5 \mathrm{~L}$ (manual samples), were filtered through a 0.45 $\mu \mathrm{m}$ polycarbonate membrane filters in a glass filtration apparatus and an aliquot of methanol of $1 \%$ of the volume of the sample was added.

Pesticides were extracted from water by Solid Phase Extraction (SPE) using $\mathrm{C}_{18}$ cartridges. The extract columns were activated with $10 \mathrm{ml}$ of ethyl acetate, $10 \mathrm{ml}$ of methanol and $10 \mathrm{ml}$ of milliQ water. The sample passed through the column at a rate of $20 \mathrm{ml} / \mathrm{min}$. Residues of water in the cartridge were avoided by drying the cartridge for 1 hour under airflow.

Compounds adsorbed on the SPE were eluted with $10 \mathrm{~mL}$ of ethyl acetate and the extract was concentrated under a nitrogen stream to $0.5 \mathrm{~mL}$ for GC injection. For the quantification of chemicals, $1 \mu \mathrm{g} / \mathrm{mL}$ of an internal standard (atratone) was added to the extract.

To assess the amount of chemicals adsorbed on particulate matter the filters were also analyzed. The filters were dried by addition of anhydrous sodium sulphate and then transferred to reaction vials. Analyte extraction was achieved with two aliquots of dichloromethane in an ultrasonic bath (20 $\mathrm{ml}$ for $30 \mathrm{~min}$, followed by $10 \mathrm{ml}$ for $15 \mathrm{~min}$ ). The two extracts were combined and were concentrated to $1 \mathrm{ml}$ with a rotavapor (Buchi, model R114) under a pressure of 300 mbar; The samples were purged and passed through columns containing $1.5 \mathrm{~g}$ of Florisil, activated with $3 \mathrm{~mL}$ of ethyl acetate and eluted with $10 \mathrm{~mL}$ of ethyl acetate. Eluates were concentrated to a final volume of $0.5 \mathrm{~mL}$ under a light nitrogen stream and $1 \mu \mathrm{g} / \mathrm{mL}$ of internal standard was added.

For the analysis, $1 \mu \mathrm{L}$ of the extract was injected in a Hewlett Parckard Model 5890 gas chromatograph, equipped with a split-splitless injector, and a Hewlett Packard model 5972 mass spectrometer as detector, managed from HP MS-Chemstation software. The capillary column was a fused silica HP $5 \mathrm{MS}, 30 \mathrm{mX0} 0.25 \mathrm{~mm}$, with a $0.25 \mu \mathrm{m}$ film thickness; helium was used as the carrier gas, with a flow of $1 \mathrm{ml} / \mathrm{min}$, and gave a column head pressure of $73 \mathrm{kPa}$. The temperature program was: oven temperature $100^{\circ} \mathrm{C}$, increased at $15^{\circ} \mathrm{C} / \mathrm{min}$ to $160^{\circ} \mathrm{C}$, increased at $2.5^{\circ} \mathrm{C} / \mathrm{min}$ to $195^{\circ} \mathrm{C}$, increased at $30^{\circ} \mathrm{C} / \mathrm{min}$ to $280^{\circ} \mathrm{C}$ held for $3 \mathrm{~min}$. Two ions for each pesticide were chosen for screening analysis in selected-ion monitoring (SIM) (Tab. 2).

A volume of $2.5 \mathrm{~L}$ of distilled water was used for recoveries of water samples and only filters were used for recoveries of suspended matter; they were spiked with standard solutions, to get recoveries at concentration of $0.04 \mu \mathrm{g} / \mathrm{L}$. The results are presented in Table 2 .

Tests with blank water samples were also performed and they didn't show any contamination.

The instrumental detection limit was $10 \mathrm{ng} / \mathrm{ml}$ of extract for terbuthylazine, metolachlor and alachlor, $40 \mathrm{ng} / \mathrm{ml}$ of extract for fenitrothion and linuron. Being the water sample volume (0.8 to 5 litres) extracted in $0.5 \mathrm{ml}$, the sample detection limit was 6 to $1 \mathrm{ng} / \mathrm{L}$ for the first group of chemicals and 25 to $4 \mathrm{ng} / \mathrm{L}$ for the second one. Due to reduced precision at the lowest concentration levels, the limit of quantification was put at $10 \mathrm{ng} / \mathrm{L} \mathrm{(30} \mathrm{ng/L} \mathrm{for} \mathrm{small-volume} \mathrm{samples} \mathrm{of} \mathrm{the} \mathrm{second} \mathrm{group).}$ Being the maximum weight of suspended matter $2.3 \mathrm{~g}$ and the samples extracted in $0.5 \mathrm{ml}$, the suspended matter's detection limit was $2.2 \mathrm{ng} / \mathrm{g}$ for the first group of molecules and $8.7 \mathrm{ng} / \mathrm{g}$ for the second one. 
Table 3. Analyte selected ions for SIM-detection, retention times, mean recovery, standard deviation, limits of detection (LOD) and limits of quantification (LOQ) in $5 \mathrm{~L}$ water samples and $2.3 \mathrm{~g}$ suspended matter (S. M.).

\begin{tabular}{|l|c|c|c|c|c|c|c|c|c|c|}
\hline \multicolumn{1}{|c|}{ Pesticide } & $\begin{array}{c}\text { Mass } \\
\text { number }\end{array}$ & $\begin{array}{c}\text { Retention } \\
\text { time } \\
\text { (min) }\end{array}$ & \multicolumn{2}{|c|}{$\begin{array}{c}\text { Mean } \\
\text { recovery }\end{array}$} & \multicolumn{2}{|c|}{$\%$ S.D. } & \multicolumn{2}{|c|}{ LOD } & \multicolumn{2}{c|}{ LOQ } \\
\hline & & & Water & S. M. & Water & S. M. & $\begin{array}{c}\text { Water } \\
\text { ng } 1^{-1}\end{array}$ & $\begin{array}{c}\text { S. M. } \\
\text { ng g }^{-1}\end{array}$ & $\begin{array}{c}\text { Water } \\
\mathrm{ng}^{-1}\end{array}$ & $\begin{array}{c}\text { S. M. } \\
\mathrm{ng} \mathrm{g} \mathrm{g}^{-1}\end{array}$ \\
\hline terbuthylazine & 214,229 & 13.22 & 100.7 & 58.0 & 12.1 & 7.2 & 1 & 2.2 & 5 & 10 \\
metolachlor & 162,238 & 17.75 & 97.0 & 48.0 & 8.5 & 7.7 & 1 & 2.2 & 5 & 10 \\
linuron & 61,248 & 17.59 & 80.0 & 52.3 & 18.1 & 4.5 & 4 & 8.7 & 20 & 40 \\
alachlor & 160,188 & 16.33 & 97.3 & 48.9 & 10.0 & 4.9 & 1 & 2.2 & 5 & 10 \\
fenitrothion & 277,260 & 17.30 & 107.5 & 55.8 & 22.4 & 3.7 & 4 & 8.7 & 20 & 40 \\
\hline
\end{tabular}





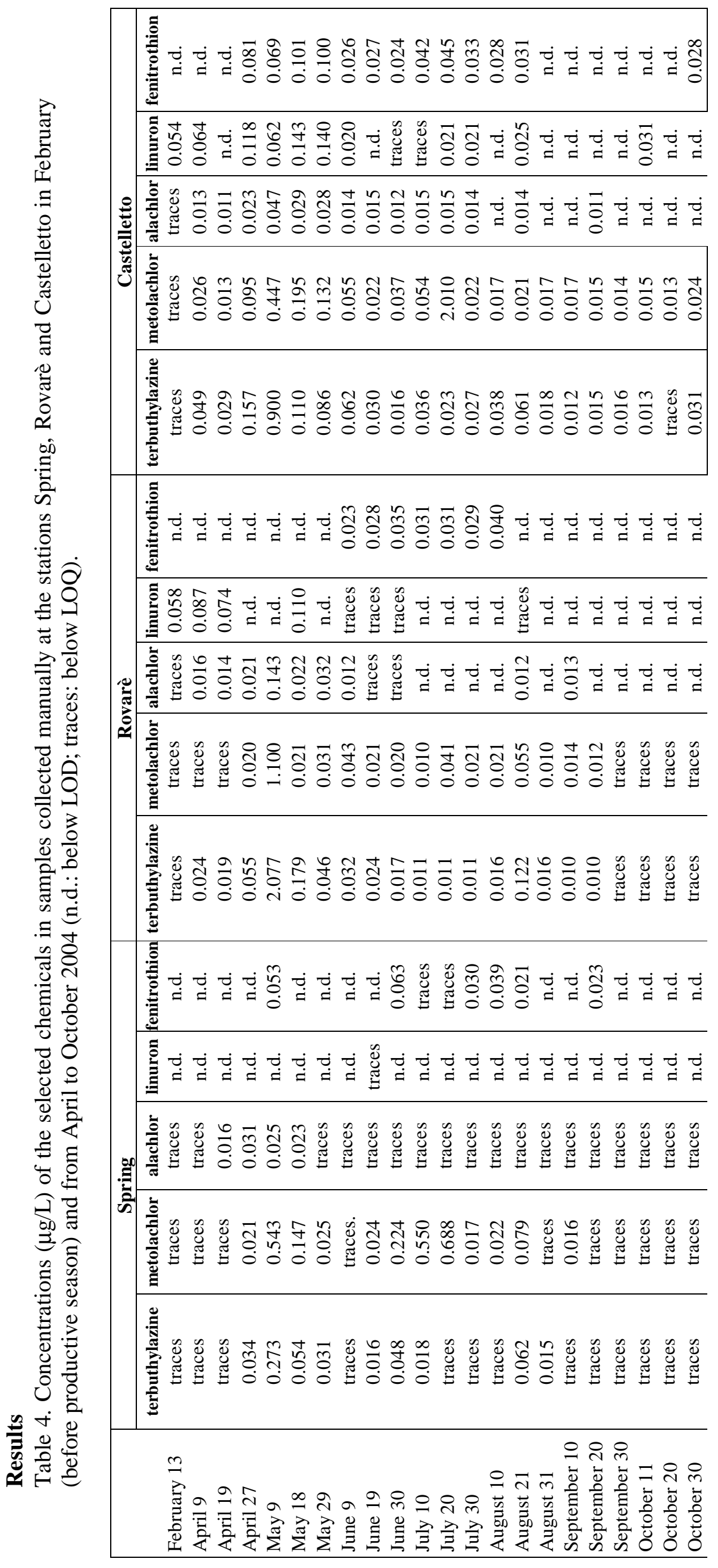


Table 5. Concentrations $(\mu \mathrm{g} / \mathrm{L})$ of the selected chemicals in samples collected by automatic sampler at the Monastier station from April to October 2004. Values reperesent daily averages of samples (n.d.: below LOD; traces: below LOQ).

\begin{tabular}{|c|c|c|c|c|c|}
\hline April 1 & $\begin{array}{c}\text { terbuthylazine } \\
0.016\end{array}$ & $\begin{array}{l}\text { metolachlor } \\
\text { traces }\end{array}$ & $\begin{array}{c}\text { alachlor } \\
0.017\end{array}$ & $\begin{array}{c}\text { linuron } \\
0.092\end{array}$ & $\begin{array}{c}\text { fenitrothion } \\
\text { n.d. }\end{array}$ \\
\hline April 2 & 0.023 & 0.013 & 0.025 & n.d. & n.d. \\
\hline April 13 & 0.043 & 0.032 & 0.019 & 0.096 & n.d. \\
\hline April 17 & 0.048 & 0.028 & 0.018 & n.d. & n.d. \\
\hline April 18 & 0.050 & 0.030 & 0.018 & 0.092 & n.d. \\
\hline April 19 & 0.045 & 0.023 & 0.031 & n.d. & n.d. \\
\hline April 20 & 0.148 & 0.014 & 0.017 & 0.090 & n.d. \\
\hline April 21 & 0.109 & 0.023 & 0.029 & 0.159 & n.d. \\
\hline April 22 & 0.253 & 0.056 & 0.036 & 0.196 & n.d. \\
\hline April 29 & 0.148 & 0.099 & 0.016 & n.d. & traces \\
\hline April 30 & 2.846 & 2.193 & 0.270 & 0.182 & 0.127 \\
\hline May 1 & 0.179 & 0.164 & 0.030 & 0.024 & traces \\
\hline May 4 & 0.439 & 0.420 & 0.032 & 0.163 & 0.068 \\
\hline May 5 & 0.538 & 0.475 & 0.053 & 0.118 & 0.060 \\
\hline May 6 & 0.781 & 0.713 & 0.101 & 0.139 & 0.065 \\
\hline May 7 & 0.633 & 0.512 & 0.078 & 0.095 & 0.069 \\
\hline May 8 & 1.902 & 1.205 & 0.196 & 0.104 & 0.062 \\
\hline May 9 & 2.830 & 1.556 & 0.189 & 0.110 & 0.062 \\
\hline May 10 & 1.366 & 0.588 & 0.085 & 0.173 & 0.121 \\
\hline May 11 & 0.402 & 0.152 & 0.026 & 0.089 & 0.061 \\
\hline May 12 & 0.488 & 0.201 & 0.034 & 0.099 & 0.067 \\
\hline May 13 & 0.130 & 0.055 & 0.021 & 0.094 & 0.066 \\
\hline May 22 & 0.110 & 0.062 & 0.016 & 0.090 & 0.063 \\
\hline May 23 & 0.068 & 0.024 & 0.020 & 0.082 & 0.058 \\
\hline May 24 & 0.034 & 0.051 & 0.016 & 0.059 & 0.042 \\
\hline June 2 & 0.294 & 0.178 & 0.087 & 0.442 & 0.313 \\
\hline June 3 & 1.001 & 0.982 & 0.083 & 0.385 & 0.268 \\
\hline June 4 & 0.271 & 0.158 & 0.072 & 0.143 & 0.274 \\
\hline June 12 & 0.180 & 0.148 & 0.015 & n.d. & traces \\
\hline June 13 & 0.091 & 0.078 & 0.038 & 0.043 & 0.059 \\
\hline June 14 & 0.103 & 0.074 & 0.044 & n.d. & traces \\
\hline July 26 & 0.060 & 0.029 & n.d. & n.d. & 0.534 \\
\hline July 27 & 0.041 & 0.030 & n.d. & n.d. & 0.332 \\
\hline July 28 & 0.044 & 0.056 & 0.027 & n.d. & 0.090 \\
\hline July 29 & 0.038 & 0.058 & 0.051 & n.d. & 0.104 \\
\hline August 3 & 0.047 & 0.056 & 0.048 & traces & 0.119 \\
\hline August 4 & 0.072 & 0.065 & 0.047 & n.d. & 0.071 \\
\hline August 5 & 0.047 & 0.053 & 0.044 & n.d. & 0.058 \\
\hline August 14 & 0.049 & 0.047 & 0.025 & 0.166 & 0.027 \\
\hline August 15 & 0.043 & 0.051 & 0.022 & 0.105 & 0.050 \\
\hline August 16 & 0.035 & 0.053 & 0.047 & 0.072 & 0.137 \\
\hline August 26 & 0.045 & 0.060 & 0.025 & n.d. & traces \\
\hline August 27 & 0.078 & 0.099 & n.d. & n.d. & n.d. \\
\hline September 15 & 0.070 & 0.102 & 0.051 & 0.081 & n.d. \\
\hline September 16 & 0.062 & 0.048 & 0.034 & 0.062 & n.d. \\
\hline September 17 & 0.042 & 0.055 & 0.050 & n.d. & n.d. \\
\hline September 18 & 0.049 & 0.048 & 0.028 & n.d. & n.d. \\
\hline October 22 & 0.014 & 0.021 & n.d. & n.d. & n.d. \\
\hline October 23 & 0.021 & 0.029 & n.d. & n.d. & n.d. \\
\hline October 24 & traces & n.d. & n.d. & n.d. & n.d. \\
\hline October 29 & 0.045 & 0.062 & n.d. & n.d. & n.d. \\
\hline October 30 & 0.046 & 0.056 & 0.020 & n.d. & traces \\
\hline October 31 & 0.039 & 0.040 & n.d. & n.d. & n.d. \\
\hline
\end{tabular}




\section{Comparison between automatic and manual samples}

A comparison between autosampler and manual data at the Castelletto station (figure 6) shows that concentrations in manual samples are always lower, demonstrating that the manual samples cannot be used to represent real runoff transport in order to assess peak concentrations. The majority of runoff peaks are missed if water sampling isn't conducted simultaneously with a rainfall event. This indicates that experimental monitoring data for pesticides in water bodies must be evaluated with care, assessing whether the reported concentrations represent either seasonal background or peak concentrations. However this is generally a problem in smaller rivers where rainfall is averaged over a small area and the river conditions are generally more diverse. Large rivers, with less variable water flow, are also characterised by a lower variability of pesticide concentration with time.

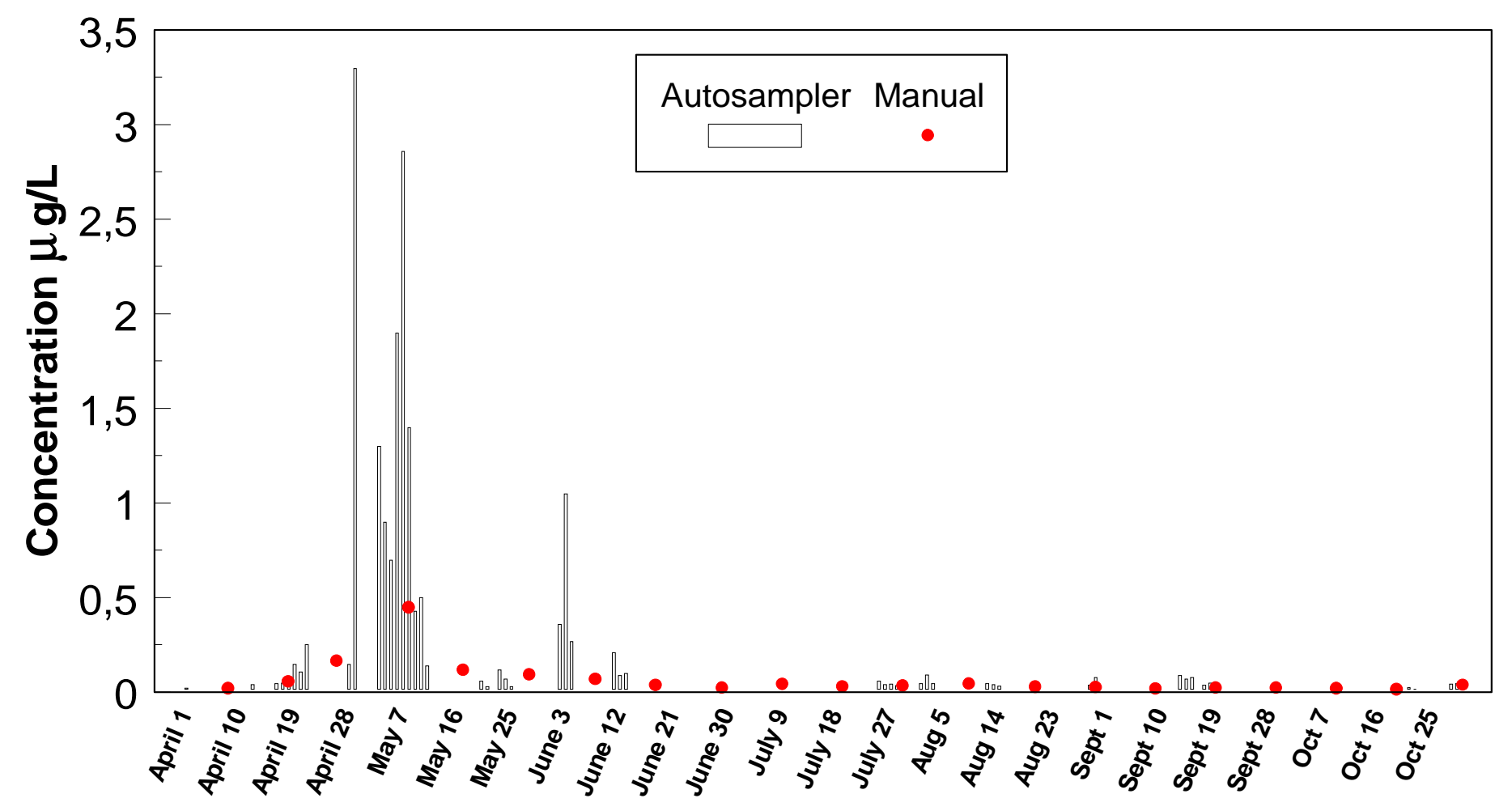

Figure 6. Comparison of terbuthylazine concentration in the automatic sampler station of Monastier and in the manual sampling station of Castelletto. 


\section{Correlation between predicted and measured concentrations}

A correlation between predicted and measured concentrations has been performed for terbuthylazine and metolachlor. The elaboration has been done using the 16 dates for which predicted and measured autosampler data were available, excluding the outlier of May $22^{\text {nd }}$. Correlation has been also performed using logarithmic transformed data, in order to better show the relationship on the whole range of variability of data, covering more than two orders of magnitude. Results of the correlations are shown in figures 7 and 8.
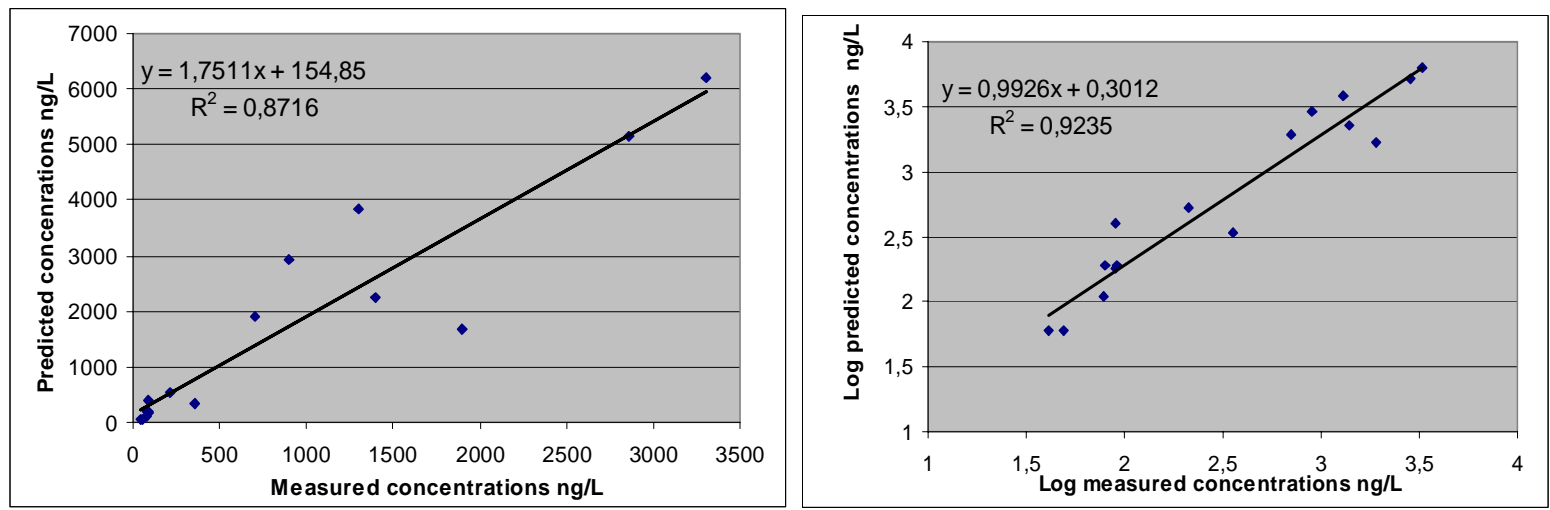

Figure 7. Linear and logarithmic correlations between predicted and measured (autosampler) concentrations for terbuthylazine.
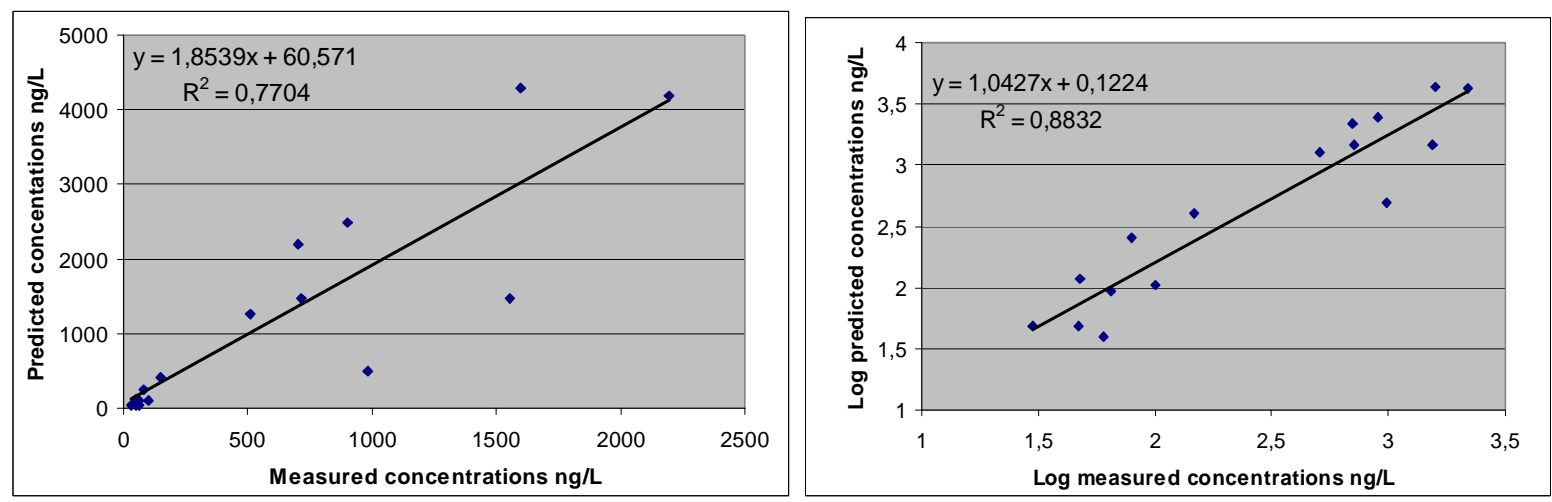

Figure 8. Linear and logarithmic correlations between predicted and measured (autosampler) concentrations for metolachlor. 